\title{
Fascial Space Infections
}

\author{
Rajasekhar Gaddipati
}

\subsection{Introduction}

There is considerable amount of change in the behavior of infections for the past one decade. The severity of infection is far greater than before which may be due to increased comorbid conditions, demanding swift action and aggressive treatment.

Fascial spaces do not exist in a normal healthy individual. These are latent spaces created by distention of tissues secondary to infection from the dental pulp, periodontal tissues and bone, where the infection perforates the cortical plate and discharge into the surrounding spaces.

The infections range from simple superficial periapical abscess to deep infections in the neck region; some resolving with little consequences and some lead to life-threatening conditions.

Shapiro states that "The fascial planes are potential areas between layers of fascia. These areas are normally filled with loose connective tissue, which readily breakdown when invaded by infection". The infection started in any area is automatically limited by tough fascial layers. If the infection becomes massive, it breaks through a nearby fascial barrier into the next fascial space [1].

\subsection{Definition of Fascial Space}

The fascial spaces in the Head and Neck are the potential spaces between the various fascia normally filled with loose connective tissue and bounded by the anatomical barriers usually of bone, muscle, or fascial layers [2].

Facial planes offer anatomic highways for infection to spread superficially to deep planes. Antibiotic availability in fascial spaces is limited due to poor vascularity.

R. Gaddipati $(\bowtie)$

Mamata Dental College, Khammam, Telangana, India

\subsection{Spread of Infection}

The spread of the infections could be either through tissues, blood, or lymphatics leading to fatal consequences like Airway obstruction, Meningitis, and Septicemia; however, various factors influence the spread of infection.

They are as follows:

- Virulence of the organism.

- Pathogenicity of the organisms.

- Immune status of the patient.

- Malnutrition.

- Thickness of bone adjacent to the offending tooth.

- Position of muscle attachment in relation to root tip.

In the Oral and Maxillofacial region, fascial spaces are almost always of relevance due to the spread of odontogenic infections. As such, the spaces can be classified according to their relation to the upper and lower teeth, and whether infection may directly spread into the space called primary space, or must spread via a primary space to the secondary space [3].

\subsection{Classification of Spaces}

\subsubsection{Primary Spaces and Secondary Spaces}

Failure to adequately treat a primary space infection or a compromised host results in secondary space involvement (Table 21.1).

\subsubsection{Cervical Spaces}

Since hyoid bone is the most important anatomic structure in the neck that limits the spread of infection, the spaces can be classified according to their relation to the hyoid bone: 
Table 21.1 Classification of spaces in odontogenic infections based on mode of involvement

\section{Mode of Involvement}

Primary spaces (Direct)

Primary maxillary spaces

- Canine space

- Buccal space

- Infratemporal space

Primary mandibular space

- Buccal space

- Sub-mental space

- Sub-mandibular space

- Sub-lingual space

Secondary spaces (Indirect)

- Masseteric space

- Pterygomandibular space

- Temporal (Superficial \& Deep) spaces

- Temporal (Superficial \& Deep) spaces

- Para-pharyngeal (Lateral \& Retro) spaces

- Pre-vertebral space

Table 21.2 Severity score for spaces [4]

\begin{tabular}{|c|c|c|}
\hline $\begin{array}{l}\text { Severity } \\
\text { score }\end{array}$ & Risk & Spaces involved \\
\hline 1 & Low risk & $\begin{array}{l}\text { Subperiosteal space } \\
\text { Vestibular space } \\
\text { Buccal and } \\
\text { Infraorbital space }\end{array}$ \\
\hline 2 & $\begin{array}{l}\text { Moderate } \\
\text { risk }\end{array}$ & $\begin{array}{l}\text { Submandibular space } \\
\text { Submental space } \\
\text { Sublingual space } \\
\text { Pterygomandibular space } \\
\text { Submasseteric space and } \\
\text { Temporal spaces }\end{array}$ \\
\hline 3 & High risk & $\begin{array}{l}\text { Lateral pharyngeal space } \\
\text { Retropharyngeal space and pretracheal space }\end{array}$ \\
\hline 4 & $\begin{array}{l}\text { Extreme } \\
\text { severe }\end{array}$ & $\begin{array}{l}\text { Danger space } \\
\text { Mediastinum } \\
\text { Intracranial infection }\end{array}$ \\
\hline
\end{tabular}

- Suprahyoid (above the hyoid).

- Infrahyoid (below the hyoid).

- Fascial spaces traversing the length of the neck.

\subsubsection{Severity Score Anatomic Space [4]}

The severity score for a given patient is the sum of the severity scores for all of the spaces involved by cellulitis or abscess, based on clinical and radiological examination (Table 21.2).

The fascial spaces are divided into:

- Spaces around the Maxilla.

- Spaces around the Mandible.

The infections arising from the maxillary anterior teeth spread to Canine space, while the infection from molars spread to Buccal space, Infratemporal space, or cause palatal abscess. Likewise, the infection from the mandibular anterior teeth spread to Submental space or cause gingival abscess. Infection from mandibular molars spread to the Sublingual space or the Submandibular space. While the infection from
Table 21.3 Characteristic features of cellulitis and abscess

\begin{tabular}{l|l|l|}
\hline Clinical feature & Cellulitis & Abscess \\
\hline Duration & Acute & Chronic \\
\hline Pain & Severe and generalized & Localized \\
\hline Size & Large & Small \\
\hline Localization & Diffuse borders & Well defined \\
\hline Palpation & Doughy to indurated & Fluctuant \\
\hline Pus formation & No & Yes \\
\hline Seriousness & Greater & Lesser \\
\hline Bacteria & Aerobic & Anaerobic \\
\hline
\end{tabular}

mandibular third molars spread to Submasseteric space, Pterygomandibular space and Lateral Pharyngeal space.

However, it is not a "rule of thumb" for the involvement of a particular space with a specific tooth infection.

\subsection{General Priciples of Management of Infection}

1. Remove the cause.

2. Establish drainage.

3. Institute antibiotic therapy.

4. Supportive care, including proper rest and nutrition.

Pyogenic infections are primarily managed by surgical intervention comprising decompression or drainage. It is better to proceed with decompression at the earliest, without waiting for the localization of the infection (abcess formation), thereby preventing the spread of infection in tissue planes and mounting of pressure under the skin (Table 21.3).

Early decompression has the following benefits:

1. Prevents the spread of infection.

2. Prevents ischemic necrosis of the tissues.

3. Prevents pressure in the tissues.

4. To get rid of toxic purulent discharge.

5. Improves the drainage, by opening the lymphatic and venous channels, which were blocked by the edema and congestion.

6. To allow better perfusion of blood thereby improving the delivery of antibiotics and defensive elements to the required site.

7. Prevents further complications.

\subsection{Hilton's Method of Abscess Drainage} (Figs. 21.1a and 21.1b)

This is a method of abscess drainage which ensures that no blood vessel or nerve in the vicinity of the incision is damaged. 
1. Topical anesthesia is achieved by ethyl chloride spray.

2. Stab incision with the help of 11 number blade is made at the most dependent area along the skin crease.

3. Sinus forceps is inserted through the incision and all the locules in the abscess are explored.

4. Purulent discharge, toxic material, gases, and necrotic tissue drained through the incision.
5. Pus collected and sent for culture and sensitivity test.

6. Abscess cavity is irrigated with antiseptic solution.

7. Corrugated rubber drain is inserted deep into the abscess cavity and secured to the edge of the incision and the drain is removed once there are no active exudates.

8. Dressing placed over the incision.
Fig. 21.1a Hilton's method of transoral incision and drainage. (a) Abscess associated with tooth. (b) Stab incision given with blade. (c) sinus forceps is entered into the cavity and opened. (d)

Drain entered into the cavity. (e) Drain secured with suture

\section{a}

a

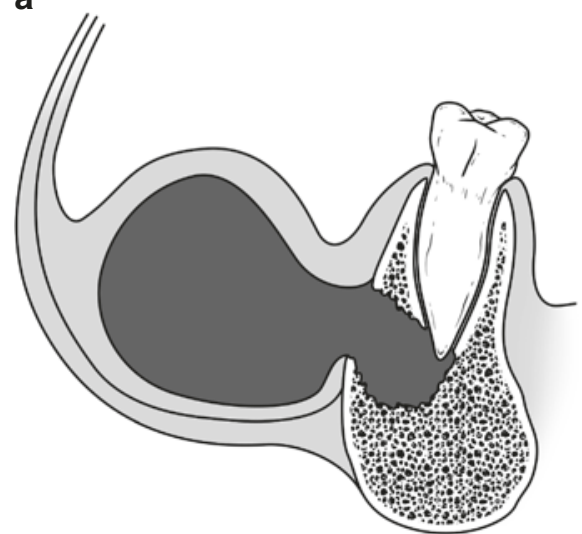

C
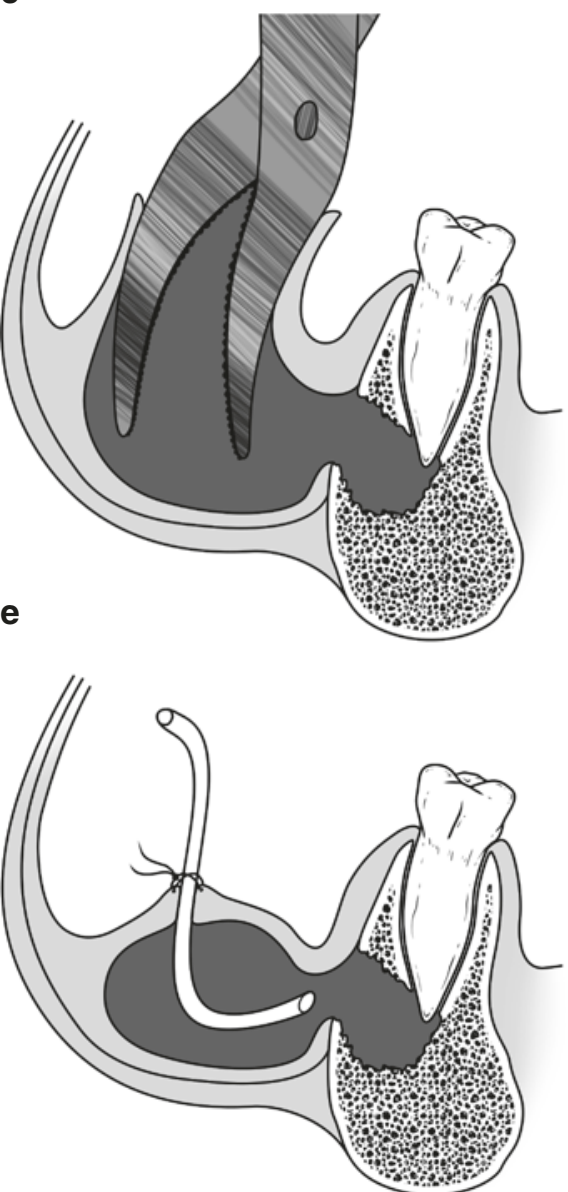

b
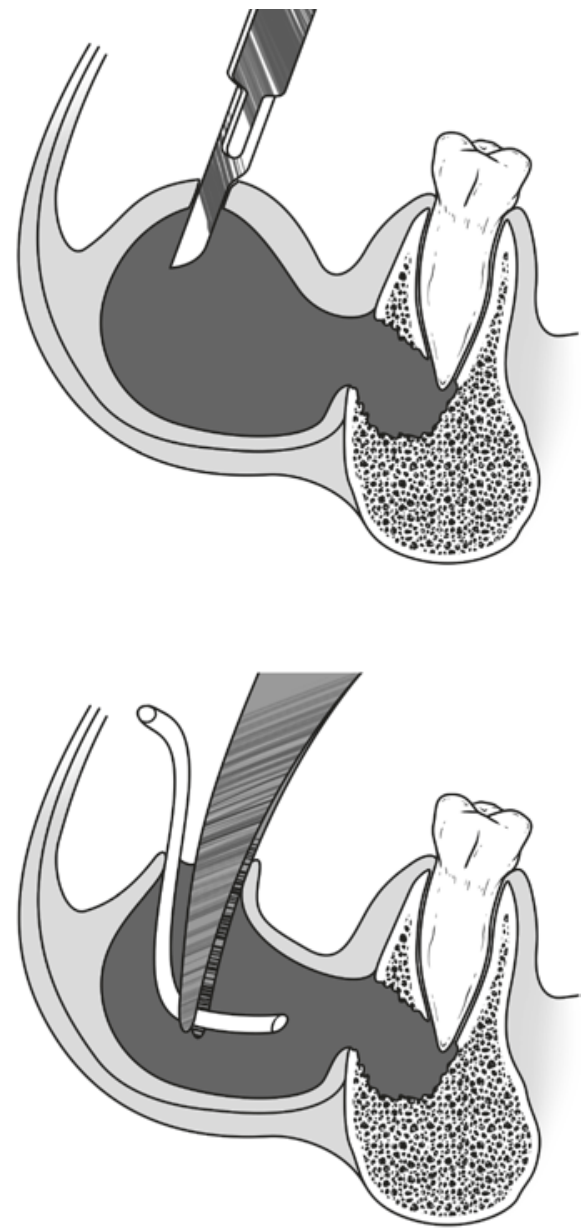
Fig. 21.1b Hilton's method of incision and drainage (extra oral site). (a) Incision given at the dependent site of the abscess. (b) Sinus forceps entered into the abscess cavity. (c) Sinus forceps opened in the cavity and removed. (d) Drain entered into the cavity and secured with suture

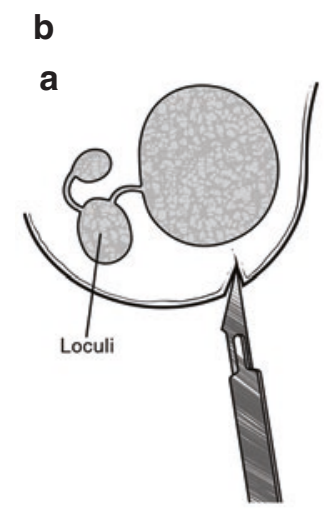

b

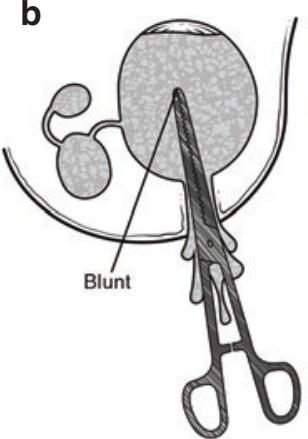

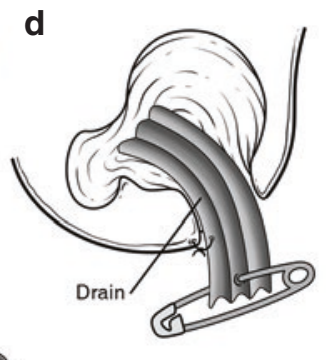

C

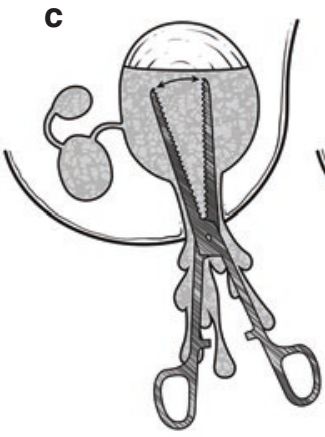

Removal of the source of the infection is mandatory apart from drainage.

\subsection{Medical Management}

Supportive management is mandatory in the form of antibiotics, anti-inflammatory, and electrolytes. The reader is also advised to refer the chapter on general principles of management of facial infections (Chap. 20).

\subsubsection{Antibiotic Therapy}

Antibiotics are advised depending upon the patient's systemic condition; initially, after pus collection, empirical antibiotic is given; later, after the culture and sensitivity is performed, -specific antibiotics are advised.

Route of administration depends upon the general condition and severity of the infection. Para-enteral route is preferred when the infection is acute and severe or when the patient is nutritionally or medically compromised.

With evidence of slough, gas, crepitus, and foul smell, anaerobic infection may be suspected and appropriate antibiotics have to be given.

Principles of choosing appropriate antibiotic

- Causative organism,

- Sensitivity,

- Specific, narrow-spectrum antibiotic,

- Least toxic antibiotic,

- Drug history (success, allergic, and toxic).

Flynn TR [5] in their systemic review concluded that antibiotics should be chosen which are safe and cost effective, because no one antibiotic is clearly superior to all others. In otherwise healthy patient, a 3-4-day regimen of antibiotic
Table 21.4 Choice of empirical antibiotics (also refer Chap. 10)

\begin{tabular}{|l|l}
\hline Severity/Penicillin allergy & Antibiotics of choice \\
\hline In patient & $\begin{array}{l}\text { Ampicillin/Sulbactam } \\
\text { Clindamycin } \\
\text { Penicillin + metronidazole } \\
\text { Ceftriaxone }\end{array}$ \\
Clindamycin \\
Moxifloxacin \\
Vancomycin + metronidazole
\end{tabular}

therapy should be adequate. The primary importance should be given to the surgical treatment consisting of incision and drainage, extraction, or endodontic therapy of the involved tooth. According to their review, the choice of empiric antibiotics for odontogenic infections is listed in Table 21.4.

Martins JR et al. [6] suggests that after incision and drainage/removal of the cause is mandatory. Antibiotics should be administered for the shortest duration possible duration and should act as an adjuvant for the primary surgical treatment in countering any regional or systemic co-morbidities.

\subsection{Fluid and Electrolytes}

Apart from antibiotics and anti-inflammatory drugs, administration of fluids and electrolytes is mandatory, as there is a loss of fluids due to infection and fever. In nonambulatory patients, intravenous fluids are administered depending on their systemic status.

Daily calorie requirement also increases by up to $13 \%$ for each degree rise in temperature, which needs to be addressed for a speedy recovery. 
Supportive therapy.

It involves those modalities which aid the patient's own body defenses. It consists of the following:

1. Administration of antibiotics.

2. Hydration of patient through IV route, maintain adequate nutritional status-high protein intake.

3. Analgesic.

4. Bed rest.

5. Application of heat in the form of moist pack, advice mouth rinses.

6. Dental management by extraction or root-canal treatment for drainage.

\subsection{Selection of Anesthesia}

A simple and superficial abscess can be drained comfortably under local anesthesia, while deep-seated, multi-loculated abcesses may not be amenable for treatment under local anesthesia and may be managed under procedural sedation provided the patient has adequate mouth-opening and patent airway.

Fiber-optic intubation or tracheostomy may be considered in; patients with limited mouth opening (trismus) or in patients having intra-oral and pharyngeal infections (sub-lingual, lateral/retropharyngeal spaces) where the chances of aspiration is high in the event of oro/naso-tracheal intubations.

\subsection{Spaces Around the Maxilla}

\subsubsection{Canine Space/Infraorbital Space}

The canine space, synonymous with Infraorbital space, is situated in the anterior surface of the maxilla at the infraorbital region above canine fossa.

\subsubsection{Source of Infection}

- From upper canine and bicuspids.

- Skin infections of upper lip [7].

\subsubsection{Boundaries (Fig. 21.2)}

- Anterior-Elevator muscles of upper lip (Orbicularis oris).

- Posterior-Anterior surface of Maxilla.

- Medial-Levator Labii Alaeque nasi.

- Lateral-Zygomaticus major.

\subsubsection{Contents}

- Angular artery and vein.

- Infraorbital nerve.
Fig. 21.2 Shows boundaries of canine (infraorbital) space

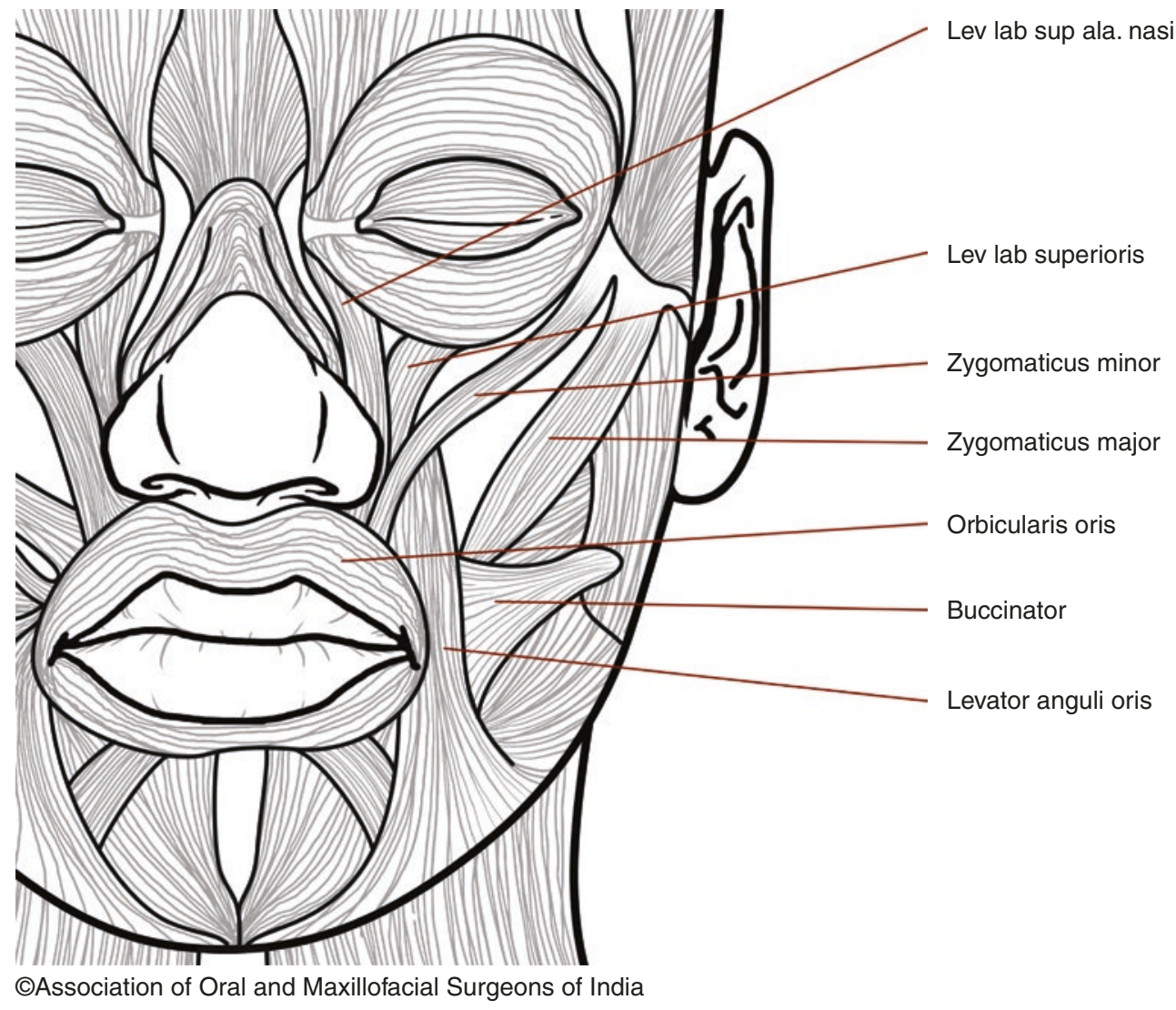




\subsubsection{Clinical Features}

1. Pain and tenderness.

2. Swelling in the anterior cheek region.

3. Obliteration of Nasolabial folds.

4. Edema of lower eyelid and upper lip.

5. Obliteration of labial vestibule.

\subsubsection{Management}

Drainage of the space infection either intraorally or percutaneously is done; intraoral incision and drainage are preferred as these will not produce a facial scar. Drainage is made by making an in-depth incision of the maxillary vestibule near canine fossa. Sinus forceps is inserted superiorly, laterally, and medially for complete breakage of locules and drainage. Care is taken while using sinus forceps, so as to not damage the infraorbital nerve and its branches.

Aggressive antibiotic therapy is mandatory to prevent the spread as it lies in the danger area of the face and also to prevent Cavernous sinus thrombosis from septic thrombi entering into angular vein.

The involved tooth is either removed or subjected to root canal treatment with multiple dressings. Patient is advised good hydration and rest.

\subsubsection{Buccal Space}

The buccal space occupies the portion of the subcutaneous space present between the fascial skin, buccinator muscle, and masseter muscle [8].

Source of infection-From maxillary premolar and molar teeth root apices above buccinator attachment.

From mandibular premolar and molar teeth root apices below the buccinator attachment.

\subsubsection{Boundaries}

- Medial: Buccinator muscle, buccopharyngeal fascia, and mucosa.

- Lateral: Skin of cheek and subcutaneous tissue.

- Anterior: Posterior border of zygomaticus major above and depressor anguli oris below.

- Posterior: Edge of masseter muscle.

- Superior: Zygomatic arch.

- Inferior: Lower border of mandible.

\subsubsection{Contents}

- Buccal pad of fat.

- Stenson's duct.

- Facial artery.

\subsubsection{Clinical Features}

1. Pain and tenderness.

2. Diffuse swelling on the side of the cheek.
3. Obliteration of buccal vestibule.

4. Swelling of upper/lower lip (Fig. 21.3).

\subsubsection{Management}

Drainage of the space infection either intraorally or percutaneously is done; intraoral incision and drainage are preferred as these may not produce a facial scar. Drainage is made by making an in-depth incision of the maxillary vestibule near the involved tooth. Sinus forceps is inserted superiorly, laterally, and medially for complete breakage of locules and drainage. Care is taken while using sinus forceps, so as to not to damage duct and artery (Fig. 21.4a, b, c).

For mandibular buccal space infection, intraoral drainage may not achieve the desired result, hence extraoral drainage at the lower border of mandible is made taking care of the facial artery and marginal mandibular nerve.

The involved tooth is either removed or subjected to root canal treatment as required. Literature advocates early extraction of the involved tooth/teeth. According to Igoumenakis D et al. [9], extraction of the involved tooth shortens the hospital stay and provides faster recovery on a biological level.

\subsubsection{Temporal Pouches}

Infections in this region are relatively rare to occur when involved swelling occurs at the temporal region above zygomatic arch and behind the lateral orbital rim [10]. They are two in number-Superficial temporal space and Deep temporal space (Fig. 21.5).

\subsubsection{Superficial Temporal Space}

This space lies between the temporal fascia and temporalis muscle.

Source of infection-From upper third molars and infection from other spaces.

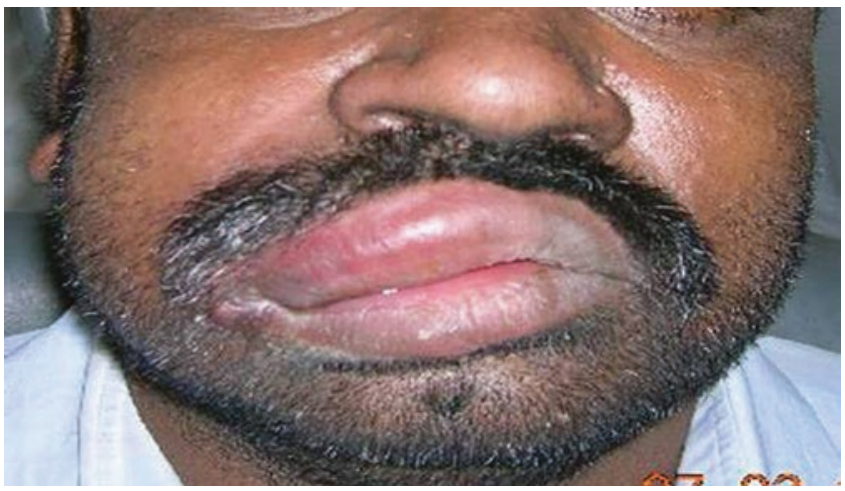

CAssociation of Oral and Maxillofacial Surgeons of India

Fig. 21.3 Clinical picture showing the buccal space infection 

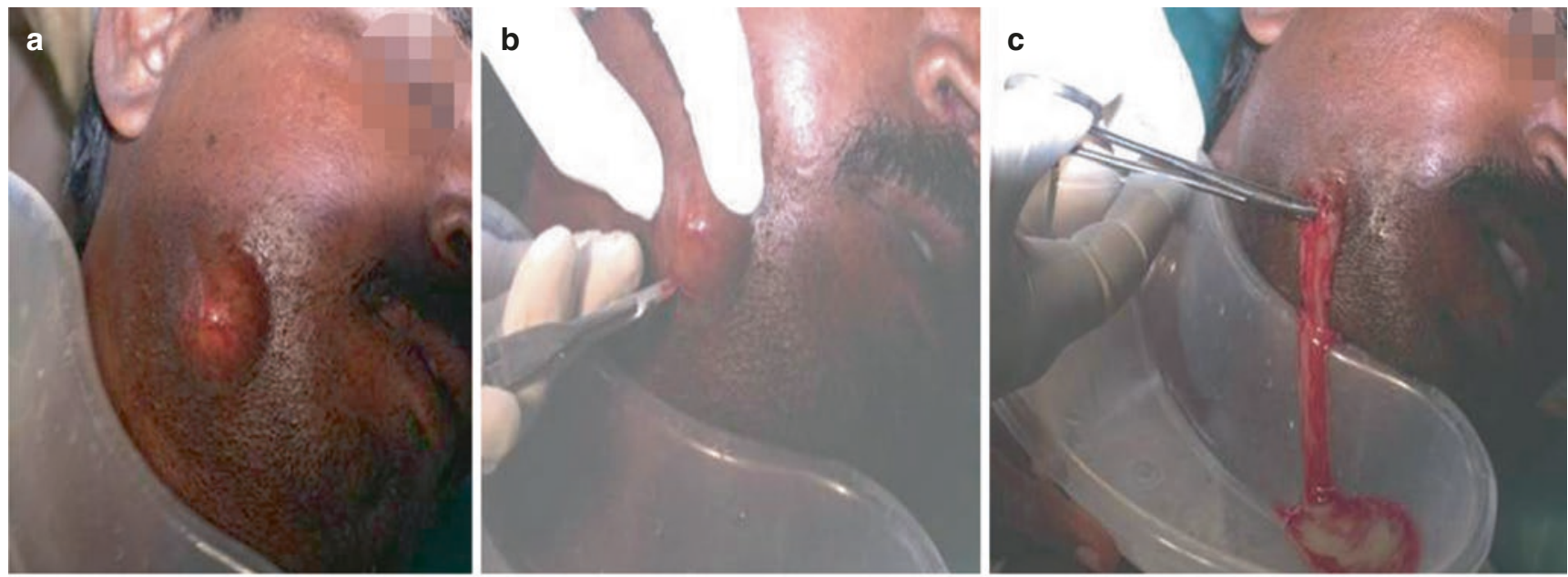

CAssociation of Oral and Maxillofacial Surgeons of India

Fig. 21.4 (a, b, c) Clinical pictures showing the procedure of incision and drainage for buccal space infection (also see Fig. 21.1B)

Fig. 21.5 Shows the superficial and deep temporal spaces

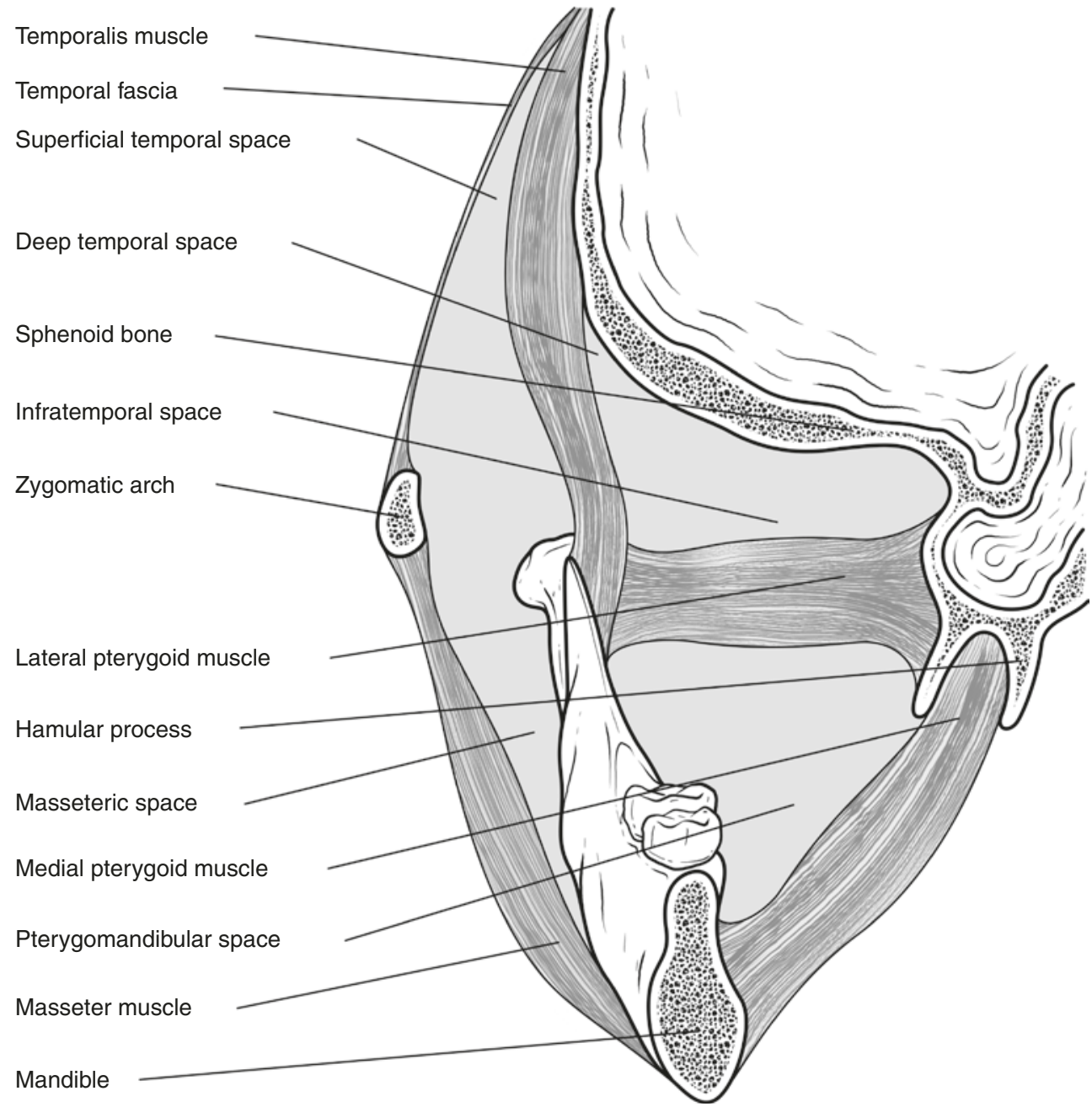

CAssociation of Oral and Maxillofacial Surgeons of India 


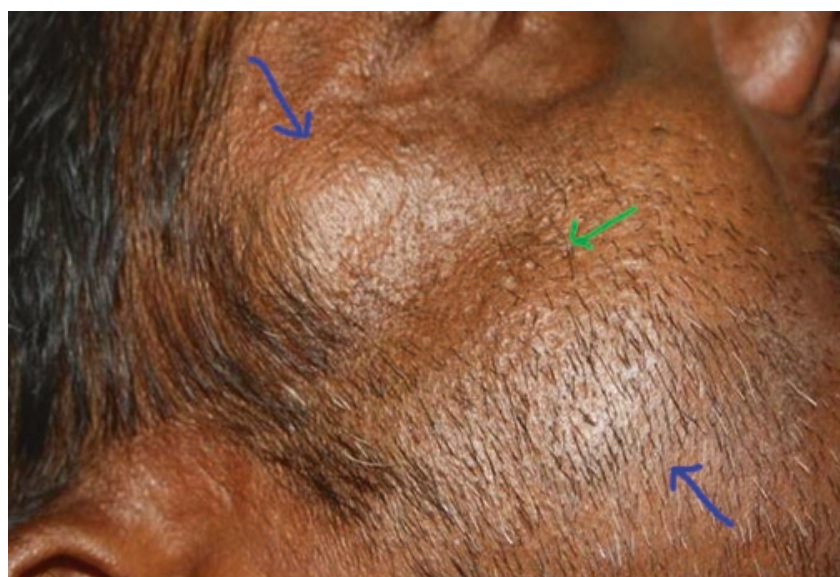

(C)Association of Oral and Maxillofacial Surgeons of India

Fig. 21.6 Clinical image of the classical dumb bell swelling (blue arrows). The isthmus of the swelling at the zygomatic arch is shown by the green arrow

\subsubsection{Boundaries}

- Superior-superior temporal lines.

- Inferior-zygomatic arch.

- Lateral-superficial temporal fascia.

- Medial-temporalis muscle.

- Anterior - posterior surface of lateral orbital rim.

- Posterior-fusion of temporal fascia with pericranium.

\subsubsection{Contents}

- Temporal fat pad.

- Temporal branch of Facial nerve.

\subsubsection{Clinical Features}

1. Pain and tenderness at the temporal region.

2. Swelling is present above and below zygomatic arch, leading to classical "Dumb bell" shaped appearance (Fig. 21.6).

3. Trismus may be present.

\subsubsection{Management}

Surgical drainage is carried out through an incision made above the zygomatic arch; sinus forceps is inserted through the skin incision and passed through the superficial fascia and the temporal fascia.

\subsubsection{Deep Temporal Space}

This space lies between the temporalis muscle and the skull. Slightly below the level of zygomatic arch; both the superficial and deep temporal spaces communicate with each other.

Source of Infection-Upper third molar and spread from other spaces.

\subsubsection{Boundaries}

- Superior-Attachment of temporal fascia to the cranium.

- Inferior-Lateral pterygoid muscle.
- Medial-Medial pterygoid plate and lower part of infratemporal fossa.

- Lateral-Medial surface of the temporalis muscle.

\subsubsection{Contents}

Branches of Internal maxillary artery.

Mandibular division of trigeminal nerve.

\subsubsection{Clinical Features}

1. Pain.

2. Swelling at the infratemporal region and lateral aspect of the eye.

3. Obliteration of buccal sulcus at tuberosity area.

4. Trismus due to proximity of masticatory muscles.

5. Infection may extend to the infratemporal and pterygomandibular region.

\subsubsection{Management}

If the trismus is not severe, intraoral incision is given in the buccal sulcus at the second and third molar region. With the sinus forceps, the space is entered medial to coronoid process superiorly and the pus is drained. Corrugated rubber tube is placed and secured with a suture.

In case of severe trismus, extraoral incision is made above the zygomatic arch at the junction of frontal and temporal process of zygoma, sinus forceps is inserted and directed inferiorly and medially to enter the space and drain the pus. The disadvantage of this approach is that it cannot produce dependent drainage.

\subsection{Spaces Around the Mandible}

\subsubsection{Submental Space}

The infection from any of the six anterior teeth in the mandible may perforate the labial bone inferior to the mentalis muscle attachment and the pus may present at the anterior and lower border of the mandible and below the mylohyoid muscle lingually [11].

\subsubsection{Source of Infection}

- Infection from lower anterior teeth.

- Infected symphyseal or parasymphyseal fractures.

- Suppuration of submental lymphnodes.

\subsubsection{Boundaries (Fig. 21.7)}

- Lateral: Skin, superficial fascia, platysma, superficial layer of deep cervical fascia.

- Medial: Mylohyoid, hyoglossus, and styloglossus.

- Inferior: Anterior and posterior belly of digastric muscles.

- Posterior: Hyoid bone.

- Superior: Medial aspect of mandible and the attachment of mylohyoid muscle. 


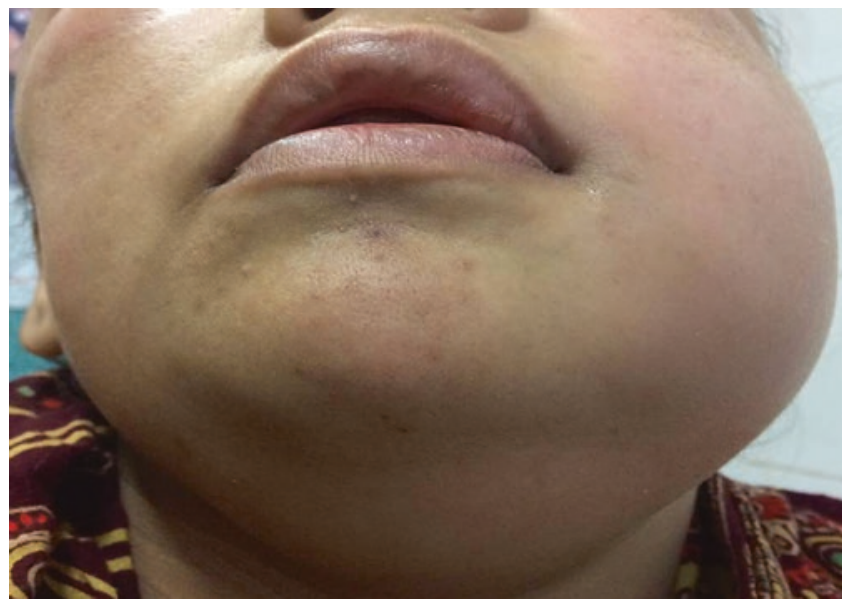

CAssociation of Oral and Maxillofacial Surgeons of India

Fig. 21.7 Clinical picture showing spread of infection to the submental space and buccal space

\subsubsection{Contents}

- Submental nodes.

- Anterior jugular vein.

\subsubsection{Clinical Features}

1. Pain and tenderness in the chin region.

2. Firm swelling at the chin.

3. Difficulty in swallowing.

4. Tenderness of lower anterior teeth.

\subsubsection{Management}

Transcutaneous approach in the chin region is the most effective drainage; incision is made below the symphysis menti to produce dependent drainage. Sinus forceps is inserted upward and backward to break the locules and the pus is drained. A corrugated rubber drain is inserted and secured with a suture. Intraoral approach is cumbersome as we need to pierce mentalis muscle to reach the submental space and also drainage against gravity is not possible.

\subsubsection{Sublingual Space}

The space is V-shaped lying lateral to the muscles of the tongue and in the lingual aspect of the body of the mandible. Anteriorly communicates with submental space and posteriorly communicates with the submandibular space at the edge of the mylohyoid muscle [12].

\subsubsection{Source of Infection}

- Periapical infection from mandibular teeth is situated above mylohyoid muscle.

- Infection from sublingual gland.

\subsubsection{Boundaries (Fig. 21.8)}

- Anterior: Lingual aspect of mandible.

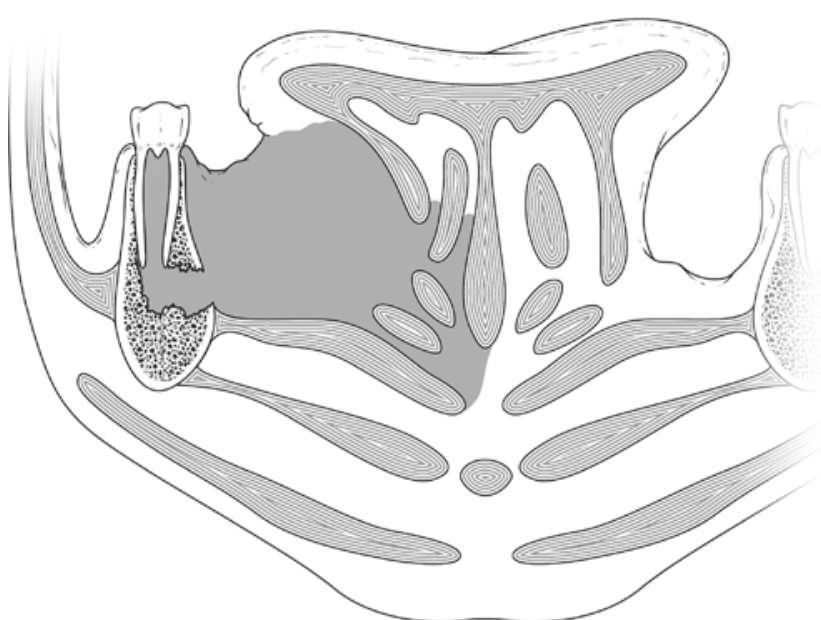

CAssociation of Oral and Maxillofacial Surgeons of India

Fig. 21.8 Shows the spread of infection to the sublingual space (grey shaded area)

- Posterior: The body of hyoid bone.

- Superior: Mucosa of oral cavity.

- Inferior: Mylohyoid muscle.

- Medial: Geniohyoid, genioglossus, and styloglossus muscle.

\subsubsection{Contents}

- Lingual nerve and Hypoglossal nerve.

- Deep part submandibular gland and duct.

\subsubsection{Clinical Features}

1. Pain and discomfort during deglutition.

2. Due to edema, there is elevation and protrusion of the tongue.

3. In case of laryngeal edema, there may be breathlessness.

4. Speech may be affected.

5. Enlarged and tender submandibular nodes.

\subsubsection{Management}

- An intraoral incision is made close to lingual cortical plate, near premolar region taking care of lingual nerve and the Wharton's duct. Sinus forceps or a thin mosquito forceps is inserted and the pus is drained.

- If an extraoral approach is planned, then incision is placed at the submandibular region, taking care of the facial artery and marginal mandibular nerve; a sinus forceps is inserted piercing the mylohyoid muscle to drain the pus and a corrugated rubber drain is inserted and secured with a suture, as this approach provides gravity-dependent drainage.

\subsubsection{Submandibular Space}

- The submandibular space is present at the inferior border of the mandible between the anterior and posterior bellies of digastric muscles [13]. 


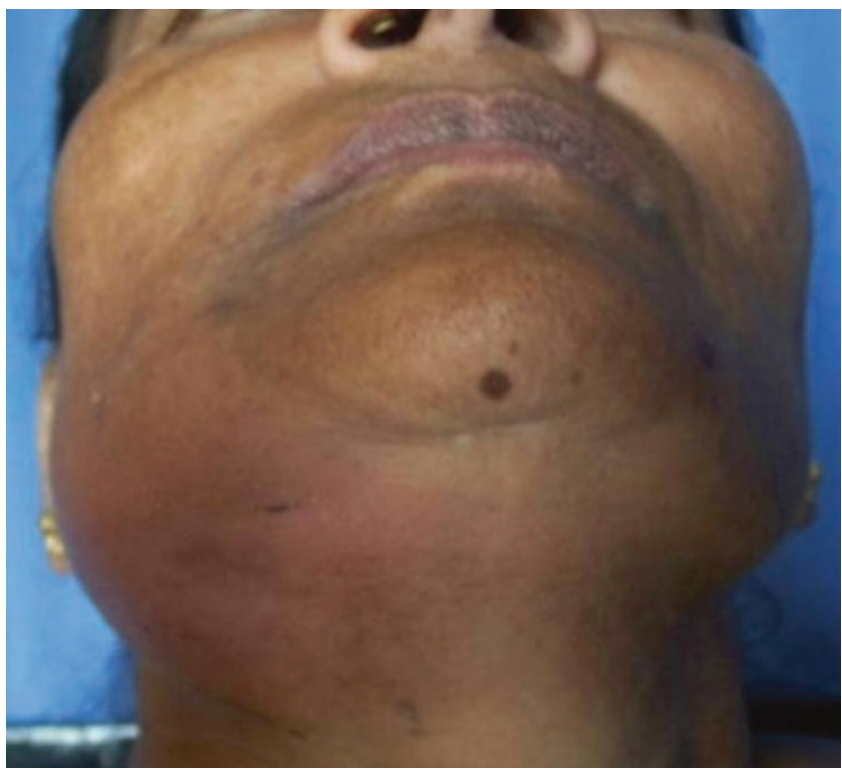

(CAssociation of Oral and Maxillofacial Surgeons of India

Fig. 21.9 Clinical picture showing the submandibular space infection

\subsubsection{Source of Infection}

- Infection from the periapical region of molar teeth below mylohyoid muscle.

- Septic fractures of the mandible body region.

- Infections from submandibular salivary gland.

- Infections from submental and sublingual.

- Infection from other space.

\subsubsection{Boundaries}

- Laterally: Skin, superficial fascia, platysma, and superficial layer of deep cervical fascia.

- Medially: Mylohyoid, hyoglossus, and styloglossus.

- Inferiorly: Anterior and posterior belly of digastric muscles.

- Posteriorly: Hyoid bone.

- Superiorly: Medial aspect of mandible and the attachment of mylohyoid muscle.

\subsubsection{Contents}

- Submandibular salivary gland.

- Submandibular nodes.

- Facial artery and vein.

\subsubsection{Clinical Features (Fig. 21.9)}

1. Pain and tenderness.

2. Swelling is situated at the submandibular region, inferior to the lower of the mandible.

3. Swelling is firm to soft in consistency.

4. Submandibular nodes are palpable and tender.

5. Intraoral - the involved teeth are sensitive.

6. Mild trismus may be noticed.

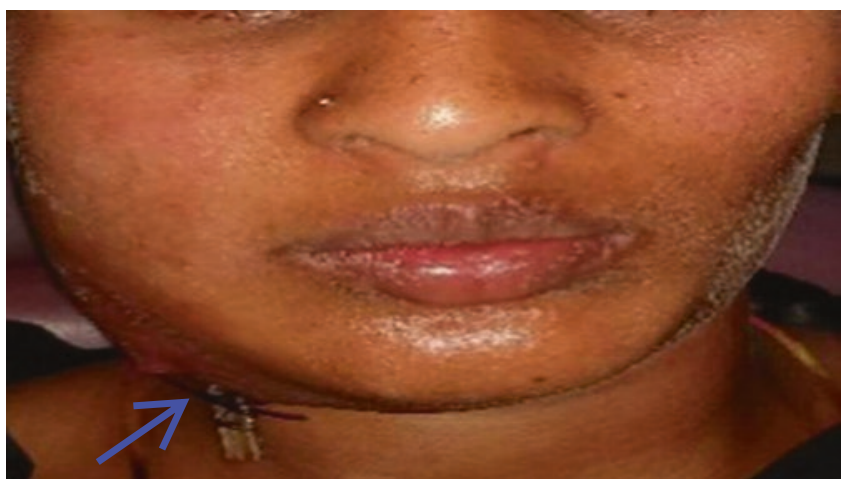

CAssociation of Oral and Maxillofacial Surgeons of India

Fig. 21.10 Clinical pictures showing drain inserted for submandibular space infection

\subsubsection{Management}

It is managed through an extraoral approach; incision is placed at the submandibular region in the most dependent area to facilitate gravitational drainage, taking care of the facial artery and marginal mandibular nerve; a sinus forceps is inserted superiorly, medially, and laterally piercing through the superficial fascia. A drain is inserted and secured with a suture to facilitate dependent drainage (Fig. 21.10).

\subsection{Masticator Space}

Masticator space is formed by splitting of the investing fascia into superficial and deep layers. The superficial layer lies along the lateral surface of the masseter and lower half of the temporalis. Deep layer passes along the medial surface of the pterygoid muscles before attaching to the base of the skull superiorly.

The masticator spaces comprise the following four spaces:

- Submasseteric space.

- Pterygomandibular space.

- Temporal space.

- Infratemporal space.

\subsubsection{Submasseteric Space}

Masseter consists of three layers which are firmly attached anteriorly and loose posteriorly. The space is present lateral to ascending ramus of the mandible. 


\subsubsection{Source of Infection}

- Infection from buccally placed lower third molar.

- Septic foci from infected angle fracture.

- Infection from other space.

\subsubsection{Boundaries}

- Anterior: Facial extension of parotidomasseteric fascia.

- Posterior: Parotid fascia and deep portion of parotid gland.

- Superiorly: Level of zygomatic arch.

- Lateral: Medial surface of the Masseter muscle.

- Medial: Lateral surface of the ramus.

\subsubsection{Clinical Features}

1. Pain and tenderness at angle mandible.

2. Moderate size swelling at the angle region.

3. Firm consistency swelling.

4. Severe trismus.

\subsubsection{Management}

The drainage of the infection is done through two approaches.

In intraoral approach, incision is placed at the retromolar area along the anterior border of the ramus of mandible. The sinus forceps is inserted through the incision laterally between the mandibular ramus and the masseter muscle to explore the Submasseteric space. The disadvantage of intraoral technique is that incision and drainage is not gravity dependent.

In extraoral approach, the incision is placed on the skin at the angle and inferior border of the mandible; sinus forceps is inserted directing superiorly piercing the subcutaneous tissue and masseter muscle. Abscess drained corrugated rubber tube is placed and secured with a suture. Precautions are taken not to damage the marginal mandibular nerve (Figs. 21.11 and 21.12).

\subsubsection{Pterygomandibular Space}

One of the most frequently encountered space in dental office is pterygomandibular space [14].

\subsubsection{Source of Infection}

- From lower third molar.

- Contaminated needle used during inferior alveolar nerve block.

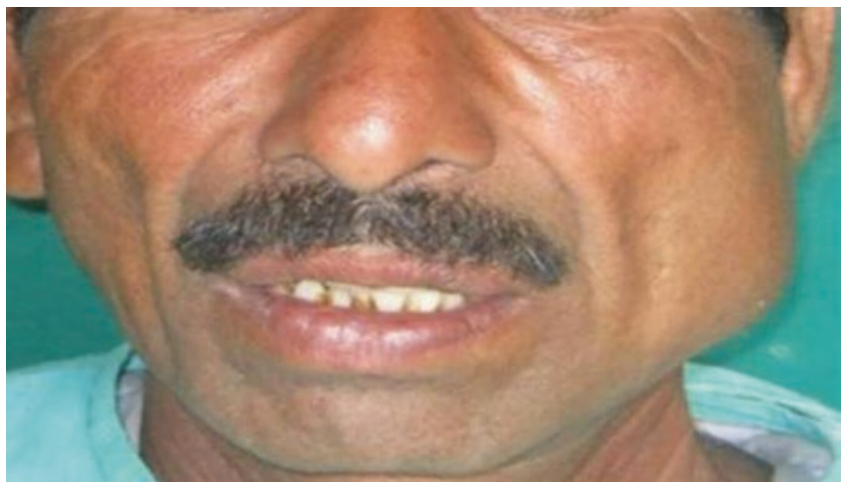

CAssociation of Oral and Maxillofacial Surgeons of India

Fig. 21.12 Clinical picture showing submasseteric space infection left side, pus was drained extraorally
Fig. 21.11 Schematic representation of approaches to the masticator spaces

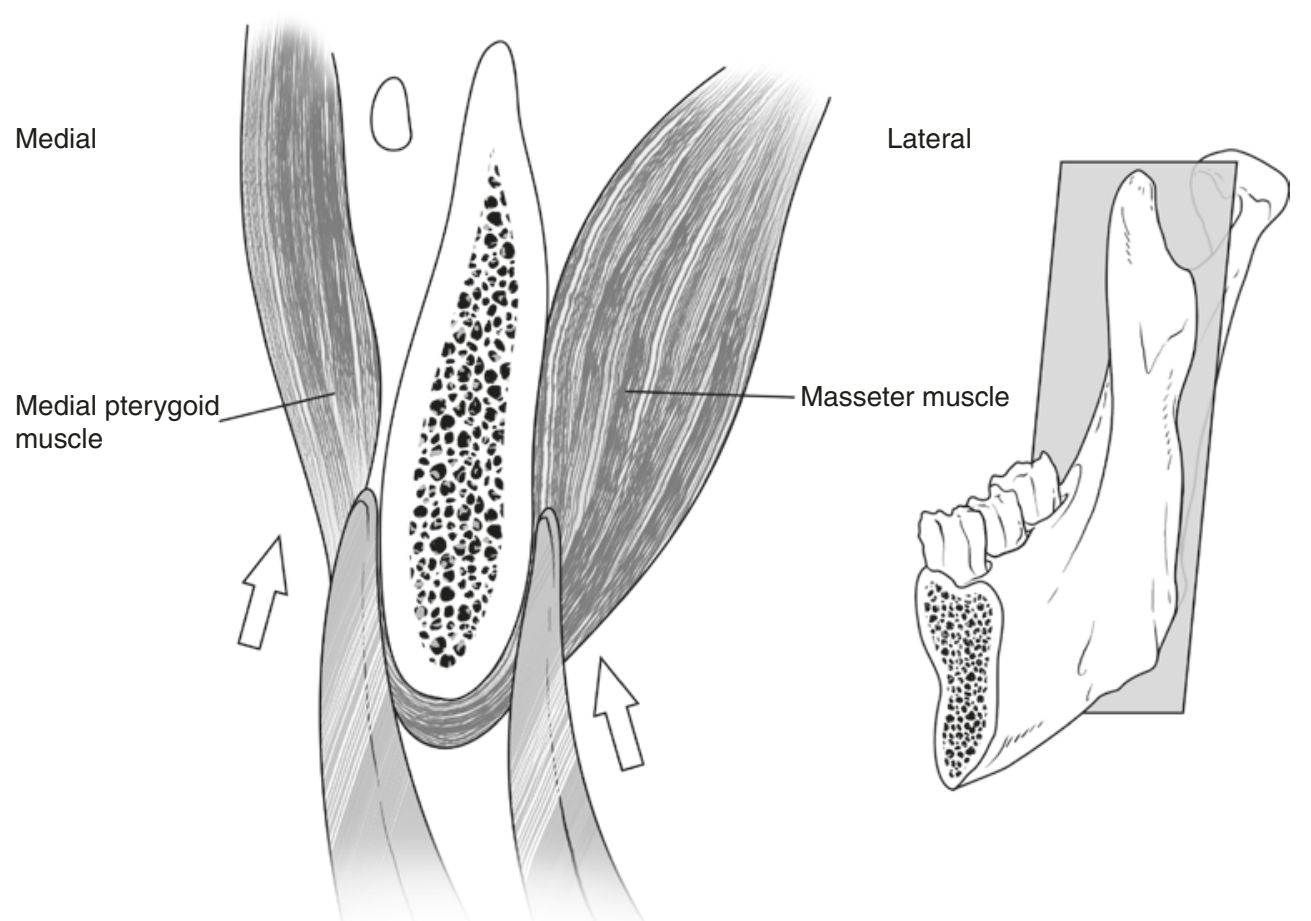


- Septic fractures of the mandibular angle.

- Infection from other spaces (Superficial temporal).

\subsubsection{Boundaries}

- Lateral: Medial surface of mandible.

- Medial: Lateral aspect of medial pterygoid muscle.

- Anterior: Pterygomandibular raphe.

- Posterior: Deep part of parotid gland.

- Superior: Lateral pterygoid muscle and infratemporal surface of greater wing of sphenoid bone.

\subsubsection{Contents}

- Inferior Alveolar Nerve and artery.

- Lingual Nerve.

- Long Buccal Nerve.

- Nerve to Mylohyoid.

\subsubsection{Clinical Features (Fig. 21.13)}

1. Pain at the retromolar region.

2. Dysphagia.

3. Trismus.

4. No obvious swelling extraorally.

5. Swelling near anterior tonsillar pillar.

6. Deviation of Uvula.

\subsubsection{Management}

Generally, incision and drainage are done through intraoral approach; however, in case of severe trismus, extraoral approach may be indicated. Drainage is done either under general anesthesia or by giving mandibular nerve block.

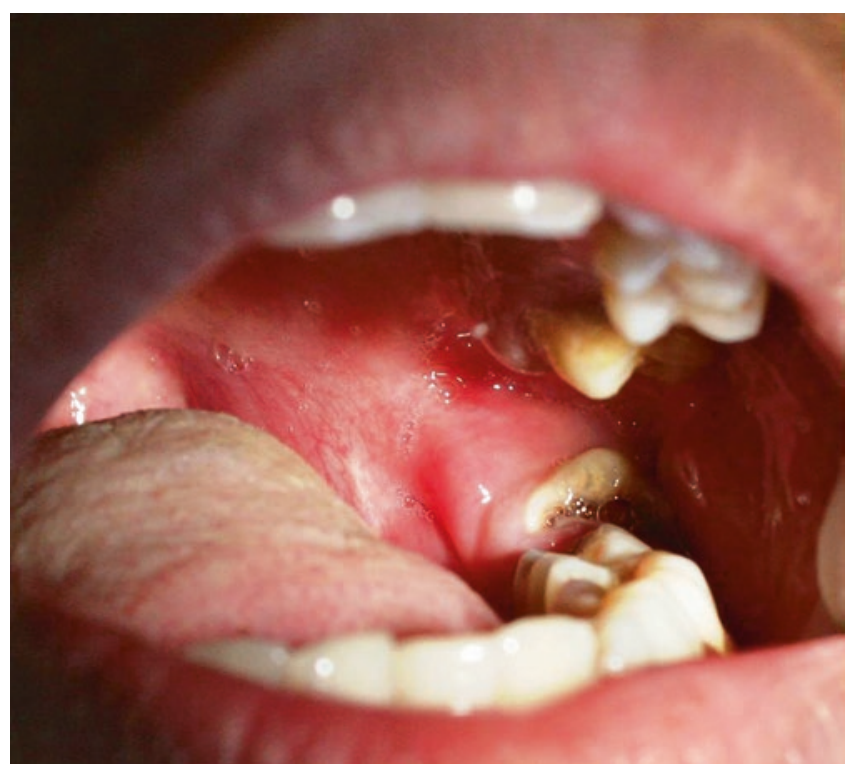

CAssociation of Oral and Maxillofacial Surgeons of India

Fig. 21.13 Clinical picture of left pterygomandibular space infection forming a decayed impacted lower left third molar. Note the limited mouth opening

\section{Intraoral Approach}

A vertical incision of $1.5 \mathrm{~cm}$ is made at the anterior and medial aspect of the mandible, sinus forceps is inserted into the abscess cavity, and pus is evacuated. Corrugated rubber drain is inserted and sutured to the margins of the incision to prevent dislodgement.

\section{Extraoral Approach}

In case of severe trismus, this approach is advised, an incision of $1.5 \mathrm{~cm}$ is made on the skin, toward the inner aspect of the angle region. Sinus forceps is inserted toward the medial aspect of the mandible directing superiorly close to the bone. Pus is evacuated and rubber drain is inserted and sutured to the margins of the incision.

Figure 21.14 shows various approaches which can be used for fascial space infections and Fig. 21.15 shows submandibular approach to the medial and lateral masticator spaces.

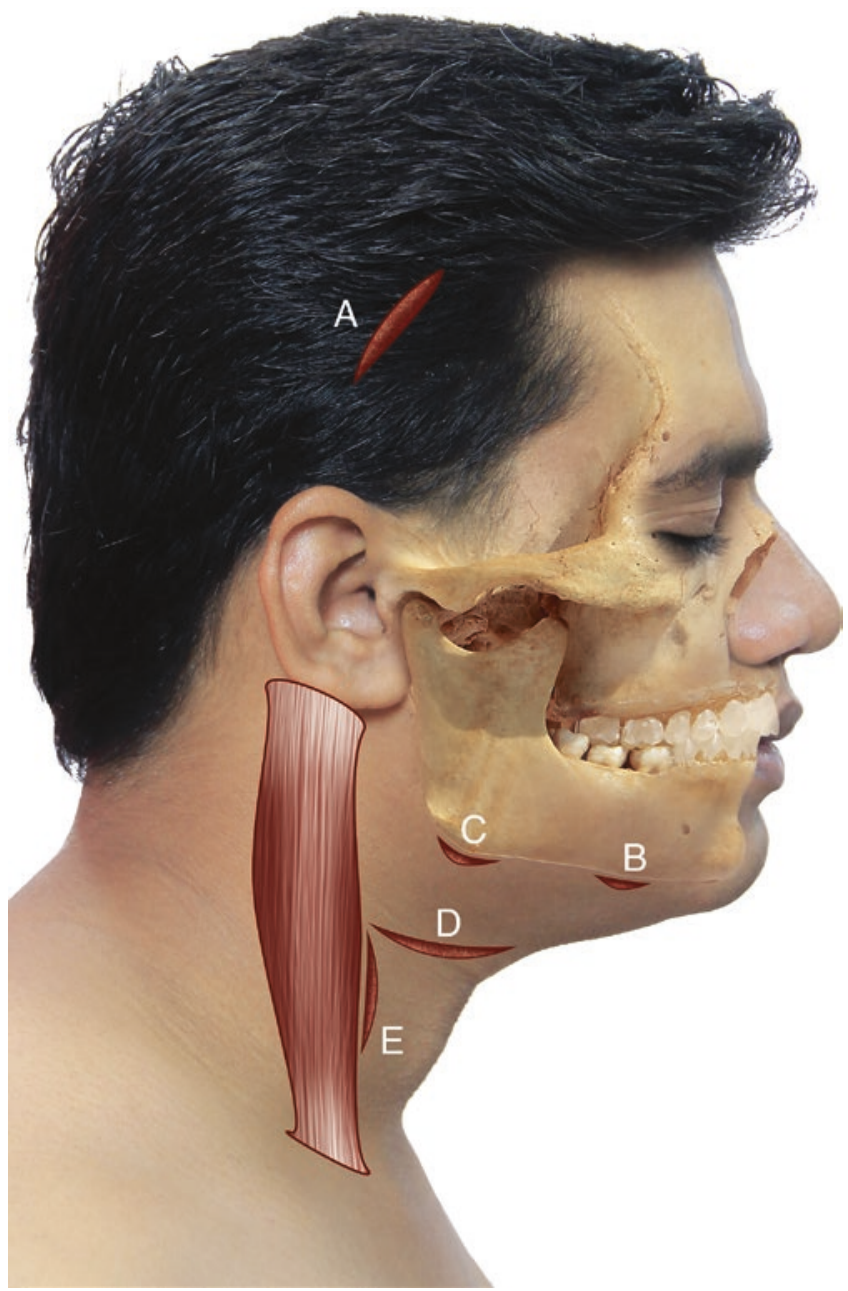

CAssociation of Oral and Maxillofacial Surgeons of India

Fig. 21.14 Shows the extraoral incisions for the space infections, (a) temporal space, (b) submental space, (c) submandibular space, (d) lateral pharyngeal space, (e) retropharyngeal space 


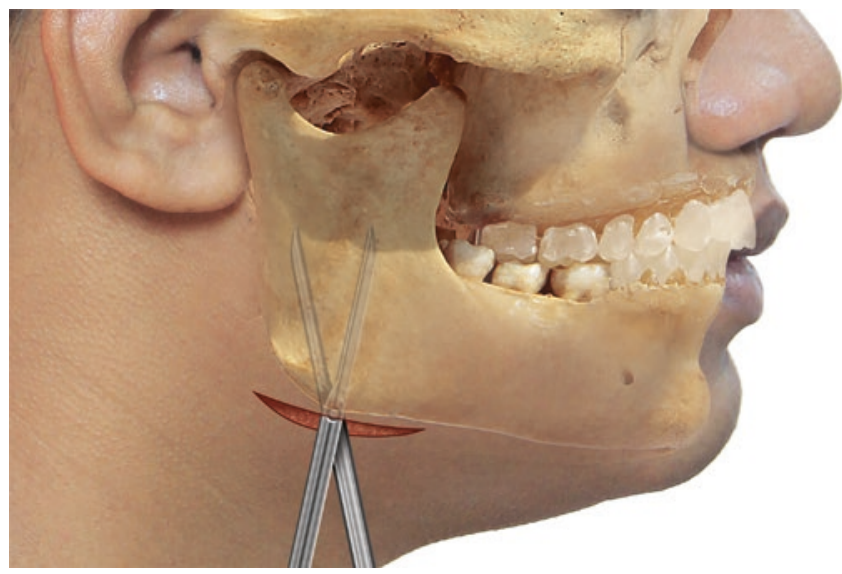

CAssociation of Oral and Maxillofacial Surgeons of India

Fig. 21.15 Diagrammatic representation of the approach to the pterygoid space (medial) or massetric space (lateral) via submandibular incision

\subsection{Spaces of Neck}

\subsubsection{Parapharyngeal Spaces}

The spaces around the pharynx form a 'Ring' and a pathway for spread of infections from the orofacial region to the neck and mediastinum. The Parapharyngeal space includes Lateral Pharyngeal space and Retropharyngeal space.

\subsubsection{Lateral Pharnygeal Space}

It is a potential space lying lateral to the pharynx, extending from base of the skull to the hyoid bone. The space is conical in shape, base being toward the base of the skull and apex toward the hyoid bone.

\subsubsection{Source of Infection}

- From other spaces which includes.

- Pterygomandibular space.

- Submandibular space.

- From Tonsils.

- From the lower third molar region.

\subsubsection{Boundaries}

- Superior: Base of the skull.

- Inferior: Hyoid bone.

- Anterior: Pterygomandibular raphe, Superior and middle pharyngeal constrictor.

- Posterior: Carotid sheath, Stylohyoid, Styloglossus, and Stylopharyngeus.

- Medial: Superior constrictor of Pharynx and Retropharyngeal space.

- Lateral: Medial pterygoid muscle, Deep lobe of the parotid gland.

\subsubsection{Contents}

- Lymph nodes.

- Ascending Pharyngeal artery and Facial artery.

- Carotid sheath.

- Glossopharyngeal nerve, Spinal Accessory nerve, Hypoglossal nerve.

\subsubsection{Clinical Features}

1. No or minimal external swelling on the lateral aspect of the neck.

2. Moderate limitation of mouth opening.

3. Rotation of neck to contralateral side is painful.

4. Dysphagia.

5. Uvula is pushed to opposite side.

6. Pharyngeal bulging is seen (Swelling over pillars of fauces and superior constrictor).

\subsubsection{Management}

A combination of intra-oral and extra-oral approaches are advised for the managment of infections of the lateral pharyngeal space. They are preferably done under general anesthesia with care taken to secure the airway.

Intraoral approach-A $1.5 \mathrm{~cm}$ incision is made on the Pterygomandibular raphe, sinus forceps is passed through the raphe on the medial surface of the mandible, medial aspect of the medial pterygoid muscle, and lateral aspect of the superior constrictor muscle.

Extraoral approach-An incision of $2.5 \mathrm{~cm}$ is made in the submandibular region, blunt dissection is then carried through the fascia just anterior to the sternocleidomastoid muscle, and digital palpation can enter and dissect the lateral pharyngeal space bluntly (Fig. 21.16). The landmarks to be palpated are the angle of the mandible anterolaterally, the carotid sheath posterolaterally, the transverse processes of the cervical vertebrae posteromedially, and the endotracheal tube, if present, anteromedially. Caution must be taken not to perforate the posterior oropharyngeal wall by aggressive finger dissection toward the oropharynx [15].

Combined approach-Intraoral incision is made on the mucosa at the medial aspect of the ramus of the mandible, curved hemostasis is inserted lateral to superior constrictor muscle and medial to medial pterygoid muscle and the blunt dissection is carried out posterio-inferiorly below the angle of the mandible. The tip of the instrument is palpated at the anterior border of the sternocleidomastoid muscle extraorally and cutaneous incision is made over the tip. A drain is inserted and sutured to the wound margin to allow drainage.

Maintaining the endo-tracheal tube or tracheostomy may be considered depending on the severity of infection and the success of drainage.

\subsubsection{Retropharyngeal Space}

It is also called as prevertebral space, which is a potential space present in the midline between the pharyngobasilar 
Fig. 21.16 Shows the approach for the retropharyngeal space infection

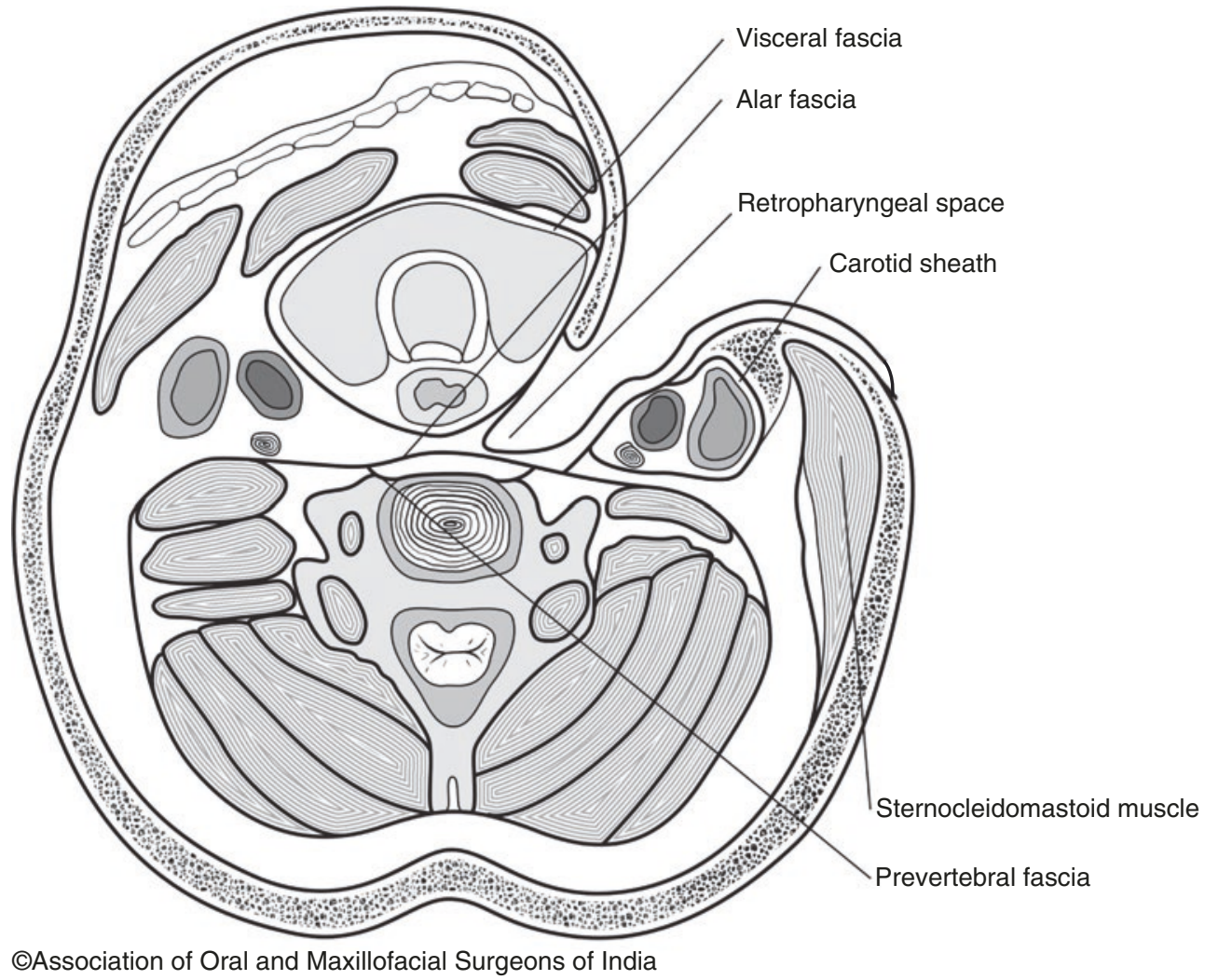

fascia and prevertebral fascia. This space is continuous with retropharyngeal space into the posterior mediastinum.

\subsubsection{Source of Infection}

- From Lateral pharyngeal space.

- From the lymph nodes that drain into Waldeyer's ring.

- Rarely from upper respiratory infections.

\subsubsection{Boundaries}

- Superior-Base of the skull.

- Inferior-Fusion of alar and Prevertebral fascia.

- Anterior-Superior and Medial constrictors.

- Posterior-Alar fascia.

- Lateral-Carotid sheath and Lateral pharyngeal space.

\subsubsection{Contents of the Space}

- Lymph nodes.

\subsubsection{Clinical Features}

1. Stiff neck.

2. Sore throat.

3. Dysphagia.

4. Lateral neck swelling and occasional erythema.

5. Fever.
6. Dyspnea.

7. Mediastinitis is the most feared complication of this space.

\subsubsection{Management}

Most important is to secure airway, may be an elective tracheostomy or fiber optic intubation is considered for airway maintenance.

Intraoral approach is generally done for the suprahyoid part of the retropharyngeal infection, procedure is similar to the one done for lateral pharyngeal space infection. Intraoral incision is made on the mucosa at the medial aspect of the ramus of the mandible, curved hemostat is inserted lateral to superior constrictor muscle and medial to medial pterygoid muscle, and the blunt dissection is carried out further inferiorly.

Extraoral approach is better for the infection at the infrahyoid region, incision is made transcutaneously anterior to the sternocleidomastoid muscle at the level of the angle of the mandible to the level of the hyoid bone. Both sternocleidomastoid muscle and Carotid sheath are identified, and retracted. Blunt dissection is carried out into lateral and retropharyngeal spaces, later being verified by the palpation of anterior process of the cervical spine posteriorly and the endotracheal tube anteriorly [16]. Drain is placed and secured to the edges of the cutaneous incision. 


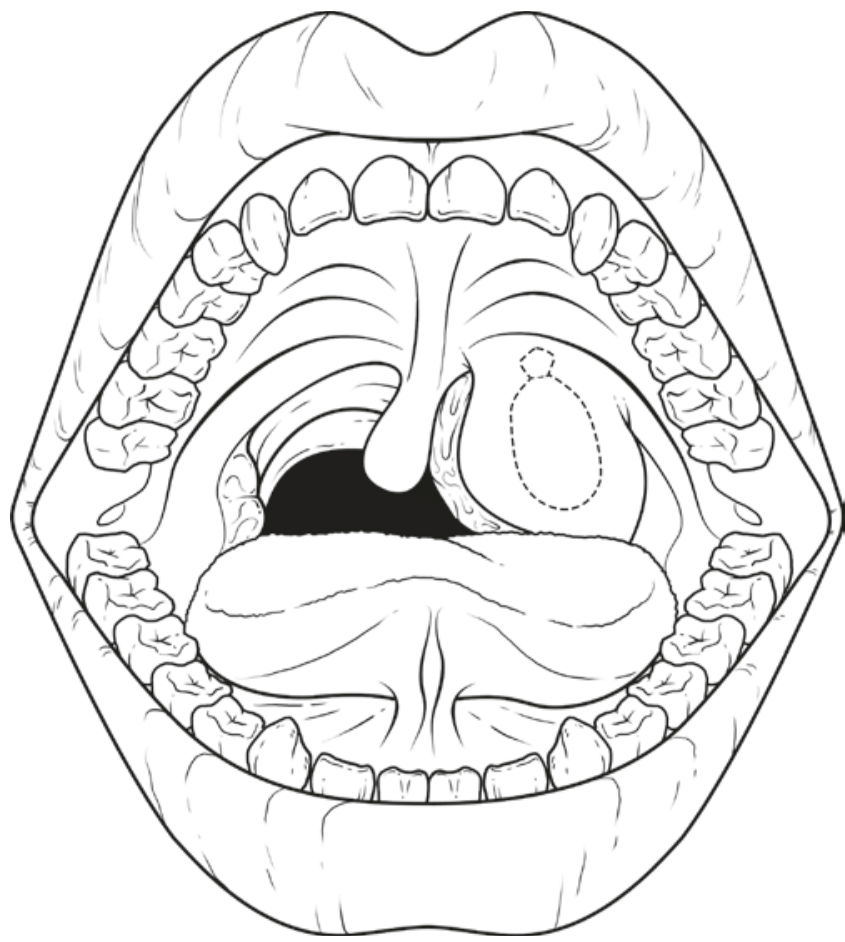

CAssociation of Oral and Maxillofacial Surgeons of India

Fig. 21.17 Shows the boundaries of peritonsillar abscess

\subsubsection{Peritonsillar Abscess: (Quincy)}

It is a localized infection near the tonsils, usually occurring as a secondary infection from the local sites.

\subsubsection{Source of Infection}

- From tonsillitis.

- Rarely from Pericoronitis.

- From Lateral pharyngeal space.

\subsubsection{Boundaries}

- Anterior-Anterior pillar of fauces.

- Posterior-Posterior pillar of fauces.

- Medially-Tonsil.

- Laterally_Superior constrictor muscle (Fig. 21.17).

\subsubsection{Clinical Features}

1. Pain in the throat radiating to ear.

2. Fever.

3. Dehydration.

4. Dysphagia.

5. Swelling visible at anterior pillar of tonsillar fauces.

6. Redness and edema may be extended to soft palate.

7. Drooling of saliva.

8. Change of voice and speech difficulty in case of bilateral involvement.

9. Mouth opening difficulty may not be present.

\subsubsection{Management}

Intraoral approach, superficial incision made at the most prominent area of the swelling near anterior pillar and the soft palate, sinus forceps is inserted deep into the tissues to break all the locules and drain the pus [17].

\subsection{Sequelae of Space Infections, if Ignored}

Possible life-threatening complications may be developed if the space infections of the jaws are not addressed adequately; for ease of understanding, the complications are classified as follows (Table 21.5).

\section{Specific warning signs in space infections include:}

- Dyspnea (difficulty breathing).

- Dysphagia (difficulty/pain with swallowing).

- Severe trismus.

- Rapidly progressive swelling.

- Edema of eyelids and abnormal eye signs.

- Impaired vision or eye movement or both.

- Change in voice quality.

- Lethargy.

- Agitation, restlessness due to hypoxia.

- Evidence of meningeal irritation-severe headache, stiff neck, vomiting.

- Decreased level of consciousness.

\subsubsection{Ludwig's Angina}

It was first described by Wilhelm Friedreich Von Ludwig in 1836, and the term Ludwig's Angina was coined by Camerer in 1937. The word Angina is derived from Latin language meaning suffocation or choking.

Ludwig's Angina is defined as an acute, firm, nonsuppurating, necrotizing cellulitis involving bilateral Submandibular, Sublingual, and Submental spaces. The condition has been described by medical practitioners, by three unique features, starting with the alphabet ' $F$ '-Feared, Fluctuant rarely, Fatal often.

Many terminologies were used for this condition like Marbus Strangularis, Angina Maligna, and Garotillo.

Table 21.5 Sequelae of space infections if ignored

\begin{tabular}{|l|l|}
$\begin{array}{l}\text { Complications from spaces around } \\
\text { mandible }\end{array}$ & $\begin{array}{l}\text { Comlications from spaces } \\
\text { around maxilla }\end{array}$ \\
\hline Ludwig's angina & Cavernous sinus thrombosis \\
\hline Necrotizing fasciitis & Meningitis \\
\hline
\end{tabular}




\subsubsection{Source}

Predominantly $(90 \%)$ odontogenic in origin, from the lower jaw.

Infection from 2 nd and 3rd molar teeth may be Acute dentoalveolar abscess, Periodontal Abscess.

- Pericoronal Abscess. Infected cyst at the body and the angle of the mandible.

- Traumatic injuries especially to the mandible, either ignored or not managed well leading to sepsis.

- Salivary gland infections.

- Iatrogenic reasons.

- Hematogenous infections.

\subsubsection{Predisposing Factors}

- Immunosuppression.

- Uncontrolled Diabetes.

- Steroid therapy.

- Debilitating conditions.

\subsubsection{Clinical Features (Table 21.6)}

The infection of the sublingual space rapidly spreads along to its base which is present at the hyoid bone. A characteristic feature is edema of the epiglottis and the vocal cords, due to the spread of infection in a postero-inferior direction from

Table 21.6 Clinical features of Ludwig's angina

\begin{tabular}{l|l}
\hline General/Systemic & Regional/Local \\
\hline Patient appears toxic & Firm to hard swelling \\
\hline Fever & $\begin{array}{l}\text { Tense, nonfluctuant, non-pitting, and wood } \\
\text { like/brawny }\end{array}$ \\
\hline $\begin{array}{l}\text { Dehydrated } \\
\text { Anorexia }\end{array}$ & $\begin{array}{l}\text { Tender } \\
\text { Malaise }\end{array}$ \\
$\begin{array}{l}\text { Difficulty in } \\
\text { swallowing }\end{array}$ & Mouth open appearance \\
\hline Hoarseness of voice & $\begin{array}{l}\text { Raised floor of the mouth } \\
\text { Shallow breathing }\end{array}$
\end{tabular}

the sub-lingual space to the laryngeal inlet. This may produce acute respiratory obstruction and death [18].

\subsubsection{Management}

It should be treated as life-threatening situation and intervened aggressively

The treatment of Ludwig's Angina is primarily surgical. The first priority in the management is always the life-saving measure. If the patient shows any signs of dyspnea, Tracheostomy should be performed promptly

Treatment protocol is as follows:

- Early diagnosis.

- Maintenance of airway.

- Intravenous broad spectrum antibiotics and fluids.

- Necessary investigations.

- Removal of the cause and surgical drainage and decompression of fascial spaces.

Endotracheal intubation is nearly impossible due to trismus, tongue elevation, and laryngeal edema. A skilled anesthetist with fiber optic laryngoscope may try Nasoendotracheal intubation, while the patient is conscious and awake, while the tracheostomy kit is kept on standby, in case of emergency (please refer Chap. 7 to read about anesthesia procedures in patients with space infections).

Once the airway is secure, the next step is surgical decompression of spaces and tissue planes; this is achieved by giving multiple cutaneous incisions in the submandibular and submental regions. Decompression of sublingual space is very important, which is achieved by piercing the mylohyoid muscle. This can also be achieved by placing an incision in the floor of the mouth, parallel to the lingual vestibule. There may not be much pus to drain as the condition is usually non-supperative (Fig. 21.18a, b, c). Corrugated rubber drain may be left in situ to keep the incisions patient and to drain the exudates [19]
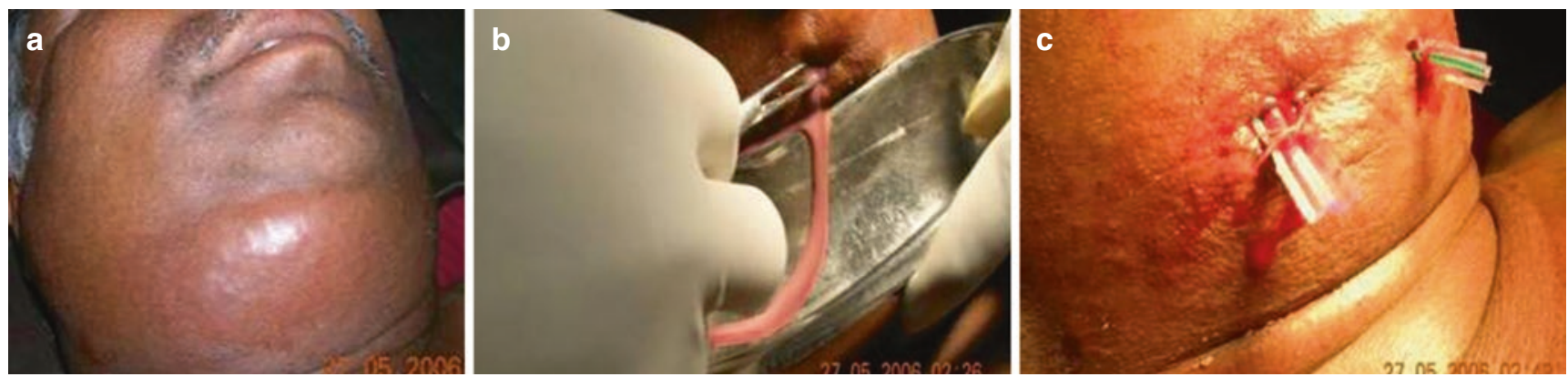

CAssociation of Oral and Maxillofacial Surgeons of India

Fig. 21.18 $(\mathbf{a}, \mathbf{b}, \mathbf{c})$ Clinical pictures showing the drainage of Ludwig's angina 
Purpose of decompression is threefold:

1. Reduces tension within the tissue planes and prevents further spread of infection.

2. As the pressure in the tissue drops, circulation improves and facilitates the reduction of the edema.

3. Drains septic material and prevents bacteremia.

After decompression, simultaneous removal of the cause is important, as this is the source of the condition.

Intravenous fluids are administered to maintain proper fluid and electrolyte balance and to fulfill the nutritional requirement of the patient. Definitive antibiotics are given intravenously based on the culture and sensitivity reports. Other symptomatic medicines like anti-inflammatory and analgesics may be prescribed. Local wound care is taken care of by irrigation and dressings. Drains to be changed every $48 \mathrm{hrs}$ and maintained until the condition resolves.

\subsubsection{Necrotizing Fasciitis}

Necrotizing fasciitis is an uncommon soft tissue infection, occurs due to polymicrobes and spreads rapidly in the subcutaneous tissue and above superficial fascia, and as the disease progresses, muscle and skin involve giving rise to myonecrosis. The other name for this condition is Hospital Gangrene given by Brooks in 1966 and Hemolytic streptococcal gangrene. Necrotizing fasciitis may affect any part of the body; however, it most commonly affects the extremities, abdominal wall, and the perineum following trauma or surgery.

The condition shows no clear boundaries or palpable limits, mainly occurs with immunocompromised patients and those suffering from systemic illnesses (Fig. 21.19).

\subsubsection{Source}

The causative organisms in this condition are multiple like Aerobic Group A-hemolytic Streptococcus and Staphylococcus and later identified microbes are Bacteroids, Proteus, coliforms, and peptostreptococcus. In most cases, the pathogens gain entry through disruption of the skin caused by trauma or surgery. Continuous bacterial overgrowth and synergy cause a decrease in oxygen tension and develop local ischemia and proliferation of anaerobic bacteria. The fulminating nature of the necrotic process is the result of the symbiotic relationship between the bacteria.

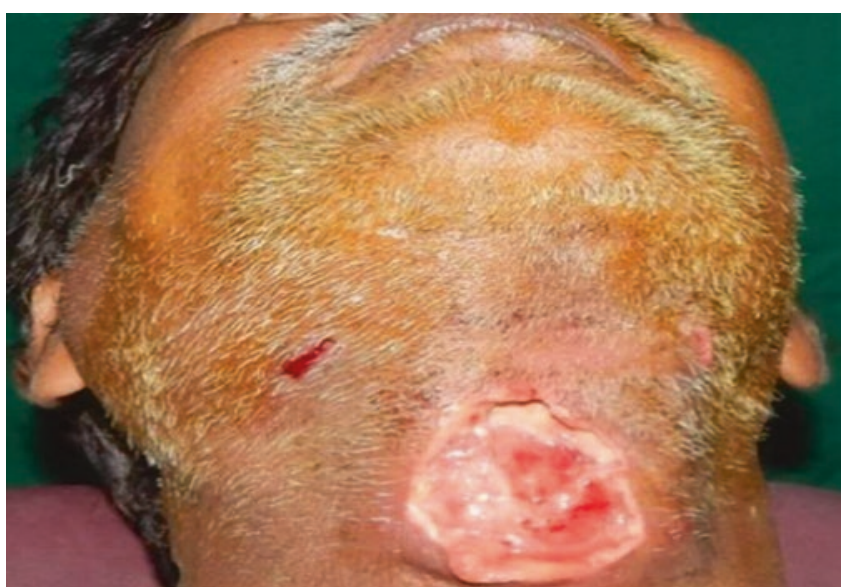

CAssociation of Oral and Maxillofacial Surgeons of India

Fig. 21.19 Clinical picture showing the necrotizing fasciitis

Table 21.7 Clinical features of necrotizing fasciitis

\begin{tabular}{|c|c|}
\hline Systemic & Local \\
\hline High fever & Involved area is swollen and erythematous \\
\hline Weakness & $\begin{array}{l}\text { Change of overlying skin color to dusky with } \\
\text { purple mottling }\end{array}$ \\
\hline Dehydration & $\begin{array}{l}\text { Visible slough on the surface with underlying } \\
\text { necrotic fascia }\end{array}$ \\
\hline $\begin{array}{l}\text { Toxic } \\
\text { appearance }\end{array}$ & Paraesthesia of the affected area \\
\hline Tachycardia & Foul smell \\
\hline \multicolumn{2}{|l|}{ Sepsis } \\
\hline Hemolysis & \\
\hline
\end{tabular}

\subsubsection{Clinical Features (Table 21.7)}

\subsubsection{Investigations}

- Complete blood picture (Leukocytosis, Band cells, and Toxic granules in Leukocytes).

- Ultrasonography of the neck-Shows the collection in the superficial planes.

- CT Scans are useful in detecting the deep-seated collections and the necrosis.

\subsubsection{Management}

Early recognition and aggressive surgical intervention is mandatory; taking the medical parameters into consideration and airway maintenance, general anesthesia is preferred in most cases.

Initially, intravenous broad spectrum antibiotics are administered to control the spread of the infection; these antibiotics may be changed once the culture report is obtained. 
Surgical treatment is obligatory with incision and drainage, in addition to vigorous debridement of the necrotic fascia, subcutaneous tissue, muscle, and skin. Excision of tissue to the point of fresh bleeding is advised. Multiple and regular change of dressings are needed till the condition is resolved.

Some centers may follow Hyperbaric oxygen therapy for this condition.

\subsubsection{Cavernous Sinus Thrombosis}

Cavernous sinuses are the venous sinuses situated on either side of the sella tursica. The cavernous sinus on either side communicates freely with each other by anterior and posterior intracavernous sinuses they also communicate with sagittal sinus, transverse, sinus and sigmoid sinus. The cavernous sinus communicates extra cranially with veins of the head and neck.

1. The ophthalmic vein and angular veins into the anterior facial vein.

2. Through emissary veins from the pterygoid plexus of veins.

External route-Infection from face and lips carried by facial and angular veins and nasofrontal veins to the superior ophthalmic vein passes through the superior orbital fissure and enters the cavernous sinus.

Internal route-Infection from the posterior maxillary region to the pterygoid plexus to the inferior ophthalmic vein through the inferior orbital fissure and then through the superior orbital fissure to the cavernous sinus.

\subsubsection{Source}

The area of the face between the inner canthus of the eyes and the corners of the mouth is called 'Danger Triangle' of the face and any kind of severe sepsis in this area can spread in a retrograde manner and can extend to the cavernous sinus through the angular vein and ophthalmic vein.

Causative agents identified are Streptococcus, Staphylococcus, and Gram negative microbes.

\subsubsection{Clinical Features}

- High fever.

- Sweating.

- Swelling (cellulitis) of the face.

- Edema, congestion, and tenderness of the eyelids.

- Ptosis.

- Exopthalmus.

- Diplopia due to involvement of 3rd, 4th, and 6th cranial nerves.
- Increased intracranial pressure due to venous congestion and cerebral edema.

- Altered level of consciousness.

- Pyogenic meningitis leading to brain abscess.

- Erosion of the internal carotid artery leading to fatal intracranial hemorrhage.

\subsubsection{Eagleton Criteria}

Diagnostic criteria were suggested by Eagleton, prior to modern investigative methods.

1. Known site of infection or septicaemia.

2. Evidence of blood stream infection.

3. Early signs of venous obstruction in the retina, conjunctiva, or eyelid.

4. Paresis of the third, fourth, and sixth cranial nerve.

5. Abscess formation in the neighboring soft tissue.

6. Evidence of meningeal irritation.

\subsubsection{Management}

The patient should be given broad spectrum intra venous antibiotics preferably those which cross the blood brain barrier. Aminoglycosides and Clindamycin are started in high therapeutic doses. IV Mannitol is given to decrease the intra cranial pressure. Anticoagulant Heparin 20,000 units in $1500 \mathrm{ml}$ of 5\% Dextrose is advised to reduce thrombosis.

Neurosurgical intervention is mandatory.

\subsubsection{Meningitis}

It is one of the neurological complications resulting from the infection of oro-facial region. It may develop from metastatic spread or may be due to nearby thrombophlebitis.

\subsubsection{Clinical Features}

1. High fever with chills

2. Irritability and mental confusion

3. Head ache

4. Vomiting

5. Stiff neck-Brudzinski's sign

6. Positive Kernig's sign

7. Convulsions

\subsubsection{Diagnosis}

Diagnosis is based on cerebrospinal fluid analysis. In CSF polymorpho-nuclear leukocytes, elevated protein levels and decreased glucose levels are noticed.

\subsubsection{Treatment}

- Initially with Chloramphenicol 4 g/day-IV associated with Penicillin G 24 million units per day IV 
- Mandatory neurosurgical consultation.

- For raised intracranial pressure IV Manniotol is given.

Maintenance of hydro-electrolyte balance is recommended. Change of antibiotics if required after culture and sensitivity report.

\subsection{Conclusion}

Odontogenic infections are typically polymicrobial. The pathogenesis of odontogenic infections depend on a synergistic relationship between aerobic and anaerobic bacteria.

The last decade showed a notable change in the behavior of odontogenic infections. The severity of these infections is far greater than in the past, demanding swift recognition of the disease followed by prompt and more aggressive treatment. Failing to identify and treat these infections promptly may result in disastrous outcomes.

Definitive treatment includes airway management, adequate resuscitation and optimization of pre-existing medical conditions prior to removal of the source of infection, and drainage of pus.

Oral and high-dose intravenous antibiotics should be administered as required depending on the severity of infection and based on the decision whether the patient is treated on an outpatient or inpatient basis, with the initial choice of antibiotics modified in the light of subsequent bacteriological reports. The treatment of all odontogenic infections must include removal of the focus of infection and drainage of pus.

\section{References}

1. Shapiro DS, Schwartz DR. Exposure of laboratory workers to Francisella tularensis despite a bioterrorism procedure. J Clin Microbiol. 2002;40(6):2278-81.

2. Standring S, editor. Gray's anatomy: the anatomical basis of clinical practice. Philadelphia: Elsevier Churchill Livingstone; 2005.

3. Guidera AK, Dawes PJD, Fong A, Stringer MD. Head and neck fascia and compartments: no space for spaces. Head Neck. 2014;36(7):1058-68.
4. Mirochnik R, Araidy S, Yaffe V. Imad Abu El-Naaj severity score as a prognostic factor for Management of Infections of odontogenic origin, a study of 100 cases. Open J Stomatol. 2017;7:25-34.

5. Flynn TR. What are the antibiotics of choice for odontogenic infections, and how long should the treatment course last? Oral Maxillofac Surg Clin N Am. 2011;23:519-36.

6. Martins JR, et al. The use of antibiotics in odontogenic infections: what is the best choice? A systematic review. J Oral Maxillofac Surg. 2017;75:2606.e1-2606.e11.

7. Grodinsky M, Holyoke E. The fascial and fascial spaces of the head and neck and adjacent regions. Am J Anat. 1938;63:367-407.

8. Ansari MK, et al. Management of Odontogenic Buccal Space Infection in patient with severe hemophilia A-case report. Int Arch Oral Maxillofac Surg. 2008;2:1-4.

9. Igoumenakis D, et al. Effect of causative tooth extraction on clinical and biological parameters of odontogenic infection: a prospective clinical trial. J Oral Maxillofac Surg. 2015;73:1254-8.

10. Fiscaletti D, Sorli A. A-temporal physical space and introduction to the theory of everything. Sci Inq. 2007;8:65-80.

11. Carter LM, Layton S. Cervicofacial infection of dental origin presenting to maxillofacial surgery units in the United Kingdom: a national audit. Br Dent J. 2009;206:73-8.

12. Kao S, Jo C, Oral and Maxillofacial Infections. Clinical review of oral and maxillofacial surgery. Mosby. 2014:95-118.

13. Rizzo PB, Da Mosto MC. Submandibular space infection: a potentially lethal infection. Int J Infect Dis. 2009;13:327-33.

14. Khoury JN, Mihailidis S. Applied anatomy of the pterygomandibular space: improving the success of inferior alveolar nerve blocks. Aust Dent J. 2011;56:112-21.

15. Qureshi FG, Newman KD. Pediatric surgery. 7th ed; 2012. p. $737-$ 43. Lymph Node Disorders

16. Albert T, Balderston R, Northrup B. Surgical approaches to the spine. Philadelphia: Saunders; 1997.

17. Scott GM, Fung K, Roth KE. Novel high-fidelity peritonsillar abscess simulator. Otolaryngol Head Neck Surg. 2016;154:634-7.

18. Farr J, Stanhope ED. Ludwigs angina. Br Med J. 1945;3:295-6.

19. Ramadhan A, et al. One incision approach to multiple facial spaces: technical note incision approach to multiple facial space. Int J Oral Care Res. 2017;5:9-14.

\section{Additional Suggested Reading}

Flynn TR. Oral and maxillofacial infections: 15 unanswered questions. Oral Maxillofac Surg Clin North Am. 2011 Nov;23(4):ix-x.

Open Access This chapter is licensed under the terms of the Creative Commons Attribution 4.0 International License (http://creativecommons. $\mathrm{org} /$ licenses/by/4.0/), which permits use, sharing, adaptation, distribution and reproduction in any medium or format, as long as you give appropriate credit to the original author(s) and the source, provide a link to the Creative Commons license and indicate if changes were made.

The images or other third party material in this chapter are included in the chapter's Creative Commons license, unless indicated otherwise in a credit line to the material. If material is not included in the chapter's Creative Commons license and your intended use is not permitted by statutory regulation or exceeds the permitted use, you will need to obtain permission directly from the copyright holder. 